\title{
Effect of Substitution of Wheat Flour with Nile Tilapia Bone Powder on The Quality Characteristics of Cashew Nut Cookies
}

\author{
Suwalee Fong-in ${ }^{1 *}$, Pattarapan Phosri ${ }^{1}$, Suttikarn Suttiprapa ${ }^{1}$, \\ Tanabodee Pimpangan ${ }^{1}$, and Niramon Utama-ang ${ }^{2,3}$
}

\begin{abstract}
${ }^{I}$ Division of Food Science and Technology, School of Agriculture and Natural Resources, University of Phayao, Phayao 56000, Thailand.

${ }^{2}$ Division of Product Development Technology, Faculty of Agro-Industry, Chiang Mai University, Chiang Mai 50100, Thailand

${ }^{3}$ Rice Product Research Unit, Faculty of Agro-Industry, Chiang Mai University, Chiang Mai 50100, Thailand

"Corresponding author.E-mail: suwalee.fo@up.ac.th

https://doi.org/10.12982/CMUJNS.2020.0062
\end{abstract}

Received: December 27, 2019

Revised: April 13, 2020

Accepted: April 20, 2020

\begin{abstract}
This study was conducted to determine the effects on the quality of cashew nut cookies substituted with Nile tilapia bone powder (NTBP), at various levels. Cookies had $a_{w}$, hardness and their spread ratio varied significantly. Color parameters showed significant changes after enhancement with NTBP. The $L^{*}, b^{*}$, and whiteness values decreased but the $a^{*}$ value increased. Results showed that the addition of NTBP significantly increased the moisture, protein, fiber and ash content of the samples, while the carbohydrate content decreased. Additionally, a drastic increase in calcium content was observed in the-substituted cashew nut cookies, when compared with wheat cookie samples used as a control. The cashew nut cookies substituting NTBP up to $20 \%$ had the highest scores of sensory properties. These results suggested that the NTBP substitution level at $20 \%$ was the suitable level which having acceptable physicochemical and organoleptic qualities while further increasing high calcium richness.
\end{abstract}

Keywords: Nile tilapia bone, Cashew nut cookies, Calcium, Substitution 


\section{INTRODUCTION}

Nile tilapia (Oreochromis niloticus) bone is a waste or by-product of processed tilapia meat, such as in the production of frozen fish fillets, fish floss, fish sausage and crispy snacks. Fish bone is, usually, not utilized for anything, but rather: is discarded as a polluting form of food waste. If weighed, it works out as about $10-15 \%$ of the total by-product of food production. In order to prepare the Nile tilapia bone powder utilized as edible ingredient, the alkaline solution procedure is frequently used due to uncomplicated, inexpensive, and effective method (Nemati et al., 2017). According to (Prapasuwannakul, 2019) (Hemung, 2013) the properties of Nile tilapia bone powder obtained from the alkaline treatment are a yellowish white color and water-insoluble. The composition of Nile tilapia bone is $40.8 \%$ protein, $25.3 \%$ total lipids, $18.3 \%$ ash and $14.2 \%$ moisture, as well as minerals $(2,715.9 \mathrm{mg}$ calcium, $1,132.7 \mathrm{mg}$ phosphorus and $1.3 \mathrm{mg}$ iron) (Prapasuwannakul, 2019). As such, fish bone is a potentially valuable resource, due to the fact it is a good source of minerals, especially: sodium, phosphorus and calcium (Hemung, 2013). It should be noted that calcium is a necessary mineral for building up healthy bones and teeth, and it is also important for the function of both the heart and muscles.

Therefore, the application of calcium fortification in food products, which increases their nutritional values, is a significant issue. There have been several studies published about the utilization of fish bone powder as a natural source of calcium and as a supplementary food ingredient. Some studies have reported the benefits of applying calcium to food products to fortify their nutritional qualities Benjakul and Karnjanapratum (2018), found that adding tuna bone bio-calcium powder to whole wheat crackers could improve their calcium and phosphorus concentration levels. They concluded that the optimum amount of tuna bone biocalcium powder they could introduce to crackers, without causing negative effects on their texture, color or organoleptic properties, was 30\%. Asikin et al. (2019), utilized knife fish bone powder as a calcium source in their kerupuk snack products, and reported that the addition of knife fish bone powder increased levels of calcium and phosphorus content. With regards to the application of Nile tilapia bone as a calcium source in food products, several studies have been produced by various researchers. Prapasuwannakul (2019), evaluated the nutritional properties and quality levels of fish crackers with different concentrations, with a substitution of tilapia bone powder instead of tapioca flour, which ranged from between $0-25 \%$ in the fish snacks. They reported that the fish crackers prepared using tilapia bone powder had an increased calcium content and that a formulation of $15 \%$ fish bone powder was found to be the better amount. Hemung and Sriuttha (2014), studied the effects of tilapia bone calcium on the quality of tilapia sausages, and concluded that the textural properties and sensory satisfaction levels for the fish sausages could be improved through the addition of extracted 
calcium fish bone. Abdel-Moemin (2015) developed flaxseed and cinnamon cookies using cooked Nile tilapia bones, and revealed that the fortification of the cookies with fish bone made them richer in terms of nutritive components, namely: fatty acids and essential minerals $(\mathrm{Ca}, \mathrm{P}$, and $\mathrm{Fe})$. Besides the nutritional impact, the effect of fish bone addition as an ingredient on the quality of food product has also been considered. Yin et al. (2014) demonstrated that the improvement of the gelling properties of Alaska pollock surimi could be achieved by adding nano-scaled Pacific whiting bone. In addition, Hemung et al. (2018) applied Silver carp (Hypophthalmichthys molitrix) bones as natural calcium source to enhance the textural properties (hardness and gumminess) of the fish emulsion sausage. Furthermore, (Nawaz et al., 2019) reported that the addition of Grass carp (Ctenopharyngodon idella) bone induced the diminished fried snacks quality attributes, such as color, expansion, and water holding capacity but improved hardness. Although some studies estimating the physicochemical and nutritional properties of fish bone powder enriched food product are available. However, investigations on the quality of bakery-based food product by addition of fish bone are rarely reported.

Cashew nut cookies are confectionary products, which have quite a slow deterioration rate, which is due to their low moisture content. Owing to their convenience as an easily acquired and eaten snack, crispness, and unique flavor, they are an enjoyable dessert or snack eaten by consumers worldwide, particularly during the Chinese New Year. They are commonly made from a mixture of the following major ingredients: wheat flour, butter, sugar as well as other minor ingredients. A cashew nut half is pressed into each cookie as a special characteristic of cashew nut cookies. To increase their nutritive content, the cookies are prepared using fortified valuable ingredients, including: dried guduchi (Tinospora cordifolia) leaf powder cookies (Sharma et al., 2013), barley flour cookies (Gupta et al., 2011) and baobab (Adansonia digitata L.) pulp flour cookies (Mounjouenpou et al., 2018). With this in mind, work was undertaken to develop healthy cookies that are fortified with Nile tilapia bone powder as a natural source of calcium. In addition, the aim was to estimate the physicochemical, microbiological properties and sensory satisfaction levels of cookies substituted with Nile tilapia bone powder at different levels.

\section{MATERIALS AND METHODS}

\section{Materials}

Nile tilapia (Tilapia nilotica) bone was obtained from a community enterprise in Phayao, Thailand. The ingredients for making cashew nut cookies, including wheat flour, butter, icing sugar, cashew nuts, palm oil, baking soda, salt and egg yolk, were purchased from a local supermarket in Phayao, Thailand. The 
chemicals used were of analytical grade (Union Science Co., Ltd., Chiang Mai, Thailand).

\section{Preparation of Nile tilapia bone powder (NTBP)}

The Nile tilapia bone powder (NTBP) was subjected to the alkaline treatment procedure, according to the method of Asikin et al. (2019). Briefly: the Nile tilapia bone was boiled in hot water at $100{ }^{\circ} \mathrm{C}$ for $30 \mathrm{~min}$; to remove any non-collagenous protein, bones were then rinsed in tap water and then soaked in a $0.8 \% \mathrm{NaOH}$ solution for $2 \mathrm{hrs}$, with the ratio of fish bone and alkaline solution at $1: 2(\mathrm{w} / \mathrm{w})$; subsequently, the bleached bones were washed with running water until there was no further residue; after washing, samples were boiled again at $100{ }^{\circ} \mathrm{C}$ for $1 \mathrm{hr}$, this step was done at least in duplicate and then bones were rinsed and drained; the washed bones were then hot air dried at $100{ }^{\circ} \mathrm{C}$ for 30 minutes and ground down into powder; to obtain a fine powder, it was then sieved using a sieve of aperture size $250 \mu \mathrm{m}$; after sieving, the obtained powder was vacuum packed and kept at room temperature.

\section{Preparation of cashew nut cookies}

The wheat flour was mixed with other ingredients for the cookie dough formulation, as follows: $47 \%$ wheat flour, $23 \%$ butter, $18 \%$ icing sugar, $7.5 \%$ cashew nut powder, $3 \%$ palm oil, $1 \%$ baking soda and $0.5 \%$ salt. The cashew nut cookies were prepared with the addition of NTBP, as a replacement of wheat flour, at the following concentration levels: $0 \%, 10 \%, 20 \%, 30 \%$ and $40 \%$. The cookies without any NTBP were used as control samples. The cookie dough was sheeted with a $0.75 \mathrm{~cm}$ thickness and then shaped using stainless steel ring molds. After that, egg yolk was lightly spread on top of the cookies, half a cashew nut was placed on top of them, and they were coated with egg yolk again. The circleshaped cookies were baked at $160{ }^{\circ} \mathrm{C}$ for 15 minutes in an electric oven and they were then left at room temperature for cooling. To remove excess moisture from the products, the cookies were dried out using a hot air oven at $100{ }^{\circ} \mathrm{C}$ for 30 minutes, and then cooled again. Finally, they were placed in airtight containers for further analysis.

\section{Assessment of cashew nut cookie properties}

Physical characteristics. The color of the cookies was measured using a colorimeter (Hunter Lab, Color Quest XE, USA) in CIELAB system: $L^{*}$ (lightness), $a^{*}$ (redness) and $b^{*}$ (yellowness) values were reported from five replications. Additionally, the whiteness index (WI) was obtained from the following equation (Gooch, 2011):

$$
W I=100-\left[\left(100-L^{*}\right)^{2}+a^{* 2}+b^{* 2}\right]^{0.5}
$$


The water activity $\left(a_{\mathrm{w}}\right)$, of the cookies was examined using a water activity meter (AquaLab 4 TE, Decagon Devices Inc., Pullman, WA, USA). The spread ratio (SR), of samples was evaluated with a Vernier caliper, by laying down and stacking three cookies on top of each other before and after baking. The spread ratio of the cookies was calculated by dividing the values of the diameter by the thickness, as shown in the following equation (Sharma et al., 2013):

$$
S R=\frac{D_{a}-D_{b}}{T_{a}-T_{b}}
$$

where $D_{\mathrm{a}}$ and $D_{\mathrm{b}}$ are the diameter value $(\mathrm{mm})$ of three cookies laid down after and before baking; $T_{\mathrm{a}}$ and $T_{\mathrm{b}}$ are the thickness value $(\mathrm{mm})$ of three cookies stacked on top of each other before and after baking.

The texture properties of the cashew nut cookies were determined using a Texture Analyzer (TA-XT Plus, Stable Micro Systems Ltd., Surrey, UK) with a 3-point bending rig at a speed of $2 \mathrm{~mm} / \mathrm{s}$, with a distance of $15 \mathrm{~mm}$ to make contact with the cookies with a $50 \mathrm{~kg}$ load cell. The peak value of the fracture force (maximum), at the point when the cookies would break into two major pieces, and distance at break was recorded as hardness $(\mathrm{N})$, and fracturability (mm), respectively. Five measurements were done for each treatment.

Chemical properties. The proximate analysis of the cashew nut cookies was done using the method of AOAC (2012). In addition, calcium content for the selected proper cookies without the adverse effect on sensory quality and control samples was estimated according to AOAC (2012). For each sample, finely ground cookies $(1.0 \mathrm{~g})$ were digested with $20 \mathrm{~mL}$ of sulfuric and nitric acid (1:3), then heated on a hot plate until dense white fumes appeared and solution became translucent. Sample was adjusted to a final volume of $25 \mathrm{~mL}$ by deionized water and the extract was subsequently filtered through Whatman No. 1 paper. Calcium level was determined using an atomic absorption spectrophotometer (AAS) (Avanta PM, GBC Scientific Equipment Pty Ltd, Australia) equipped with deuterium lamp. Calcium compound was atomized in an air-acetylene flame and absorbance was then measured at $422.7 \mathrm{~nm}$ with a $0.2 \mathrm{~nm}$ slit width. Each sample was investigated in triplicate and calcium content was expressed as $\mathrm{mg} \mathrm{g}^{-1}$.

Sensory evaluation. The cashew nut cookies were coded with 3-digit numbers and served to 30 untrained panelists. The judges were asked to score the cookie samples for appearance, color, flavor, taste, texture, and their overall liking of them. The scoring was based on a 9-point hedonic scale, where 1 represented extreme dislike and 9 the opposite extreme. 


\section{Statistical analysis}

The results were expressed as the mean \pm standard deviation. The data was subjected to ANOVA using IBM SPSS Statistic 22.0 software and the Duncan's new multiple range test to find out the significant differences of mean values between treatments at level $P<0.05$.

\section{RESULTS}

\section{Physical characteristics of cashew nut cookies substituted with Nile tilapia bone powder}

The characteristics of NTBP in this work were observed. The overall appearance of the obtained NTBP was of creamy-colored powder and slightly grittiness particles. Also, there was no fishy odor in the sample, which might be helpful for its application in several food products as a source of calcium. In Table 1 , results obtained for the color measurements of the NTBP are displayed. The lightness $\left(L^{*}\right)$, redness $\left(a^{*}\right)$, yellowness $\left(b^{*}\right)$ and whiteness values of the NTBP were $91.88,0.51,11.26$ and 86.11 , respectively. Furthermore, the NTBP was found to a dried powder with very low $a_{\mathrm{w}}(0.316)$.

The color parameters of the cashew nut cookies substituted with NTBP, at different ratios, are listed in Table 1 . The tendency of the lightness $\left(L^{*}\right)$ and yellowness $\left(b^{*}\right)$ values decreased when the NTBP level was increased. The lowest $L^{*}$ and $b^{*}$ values were observed in the cookies that contained $40 \%$ NTBP $(P \leq 0.5)$. Whereas, the redness $\left(a^{*}\right)$ value slightly increased as more NTBP was added, and was found to be its highest level at $40 \%$ NTBP $(P \leq 0.5)$. Besides, the whiteness index of the cashew nut cookies slightly decreased significantly $(P \leq 0.5)$ as NTBP concentration increased. The whiteness of the cookies contained NTBP at various levels was observed in the range 65.52 to 68.17 (Table 1). Additionally, the cookies substituted with $40 \%$ NTBP were found to have the lowest levels of whiteness index.

Table 1. Color, water activity, and spread ratio of cashew nut cookies substituted with different NTBP levels.

\begin{tabular}{|c|c|c|c|c|c|c|}
\hline \multirow{2}{*}{ Samples } & \multicolumn{4}{|c|}{ Color parameter } & \multirow{2}{*}{$a_{\mathrm{w}}$} & \multirow{2}{*}{$\begin{array}{c}\text { Spread } \\
\text { ratio }\end{array}$} \\
\hline & $L^{*}$ & $a^{*}$ & $b^{*}$ & WI & & \\
\hline NTBP & $91.88 \pm 0.21$ & $0.51 \pm 0.04$ & $11.26 \pm 0.09$ & $86.11 \pm 0.15$ & $0.316 \pm 0.00$ & - \\
\hline $0 \%$ NTBP & $79.57 \pm 0.71^{\mathrm{a}}$ & $3.68 \pm 0.46^{b}$ & $24.12 \pm 0.43^{\mathrm{a}}$ & $68.17 \pm 0.68^{\mathrm{a}}$ & $0.134 \pm 0.01^{\mathrm{c}}$ & $3.38 \pm 0.07^{\mathrm{d}}$ \\
\hline $10 \%$ NTBP & $78.93 \pm 0.76^{\mathrm{ab}}$ & $3.71 \pm 0.47^{\mathrm{b}}$ & $24.24 \pm 0.36^{\mathrm{a}}$ & $67.66 \pm 0.47^{\mathrm{ab}}$ & $0.166 \pm 0.01^{\mathrm{b}}$ & $3.60 \pm 0.03^{c}$ \\
\hline $20 \%$ NTBP & $78.14 \pm 0.57^{b}$ & $3.61 \pm 0.33^{b}$ & $24.00 \pm 0.38^{\mathrm{a}}$ & $67.33 \pm 0.22^{\mathrm{b}}$ & $0.173 \pm 0.02^{\mathrm{b}}$ & $3.70 \pm 0.13^{\mathrm{bc}}$ \\
\hline $30 \%$ NTBP & $78.43 \pm 0.64^{b}$ & $3.86 \pm 0.25^{\mathrm{b}}$ & $24.52 \pm 0.31^{\mathrm{a}}$ & $67.11 \pm 0.55^{b}$ & $0.192 \pm 0.01^{\mathrm{b}}$ & $3.78 \pm 0.06^{\mathrm{b}}$ \\
\hline $40 \%$ NTBP & $74.98 \pm 0.38^{\mathrm{c}}$ & $4.65 \pm 0.32^{\mathrm{a}}$ & $23.26 \pm 0.52^{\mathrm{b}}$ & $65.52 \pm 0.54^{\mathrm{c}}$ & $0.254 \pm 0.01^{\mathrm{a}}$ & $4.15 \pm 0.06^{\mathrm{a}}$ \\
\hline
\end{tabular}

Note: In each column, different letters represent significant differences $(P \leq 0.05)$. 
Additionally, the results of this study have shown that there was a significant difference $(P \leq 0.05)$ between each of the samples in terms of the $a_{\mathrm{w}}$ and spread ratio (Table 1). The $a_{\mathrm{w}}$ level of the cookies ranged from 0.134 to 0.254 . The results revealed an increasing trend where by the $a_{\mathrm{w}}$ increased as the substitution level of NTBP powder was increased. The spread ratio ranged from 3.38 to 4.1. It was observed to be at its highest value in cashew nut cookies when they were made from $40 \%$ NTBP, this can be seen below in Figure 1, which shows how the appearance of the cashew nut cookies, replaced with various amounts of NTBP, changed.

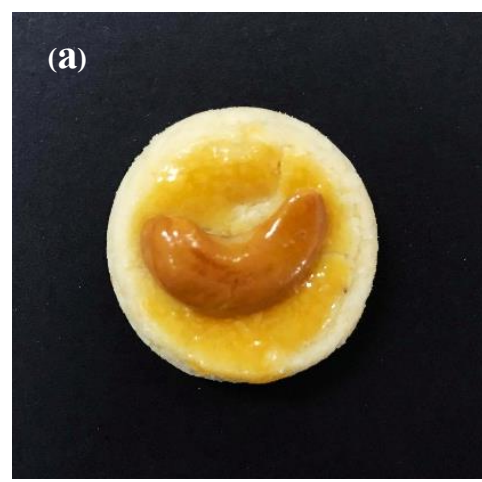

Control

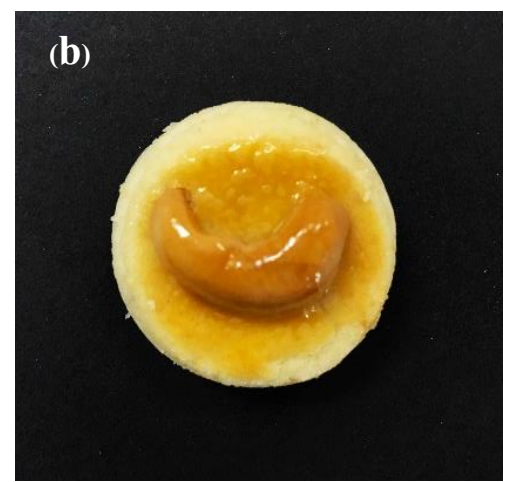

$10 \%$ NTBP

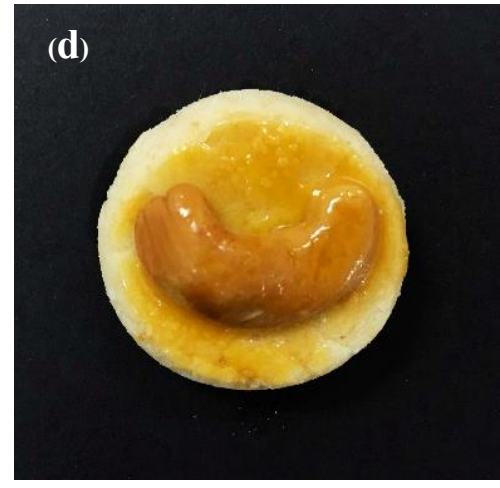

$30 \%$ NTBP

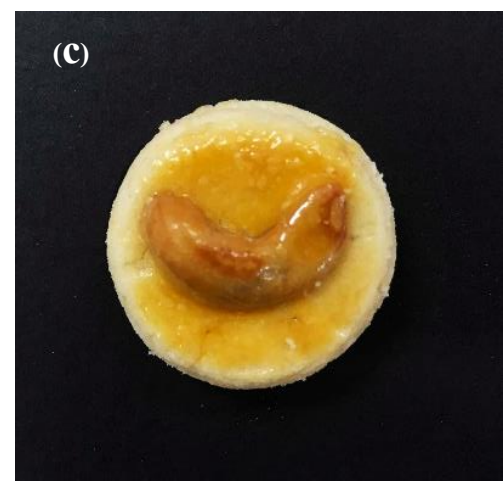

$20 \%$ NTBP

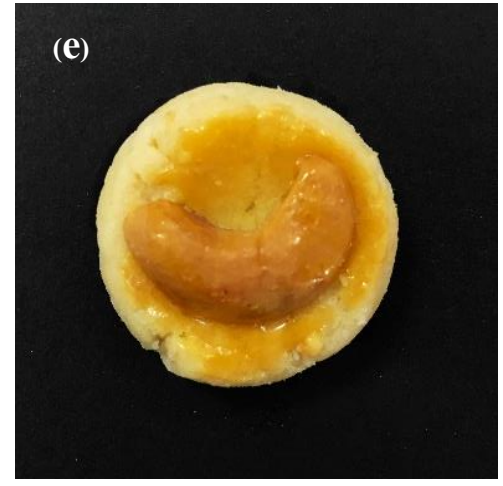

$40 \%$ NTBP

Figure 1. Appearance of cashew nut cookies substituted with NTBP, (a) control; (b) $10 \%$ NTBP; (c) $20 \%$ NTBP; (d) $30 \%$ NTBP; and (e) $40 \%$ NTBP.

The acceptable characteristics of the cookies was measured in terms of hard or brittle properties (Cheng and Bhat, 2016). Data about the texture of the cookies showed a significant change in the hardness and fracturability values, as displayed in Figure 2. All of the cashew nut cookies that contained NTBP had a higher level of hardness than the control samples $(P \leq 0.05)$. The hardness value of cookies ranged from 16.69 to $25.84 \mathrm{~N}$. The results showed that NTBP 
decreased the fracturability of cookies from $1.15 \mathrm{~mm}$ to $0.74 \mathrm{~mm}$, and the lowest level of fracturability was noticed in cookies composed of $40 \%$ NTBP $(P \leq 0.05)$.

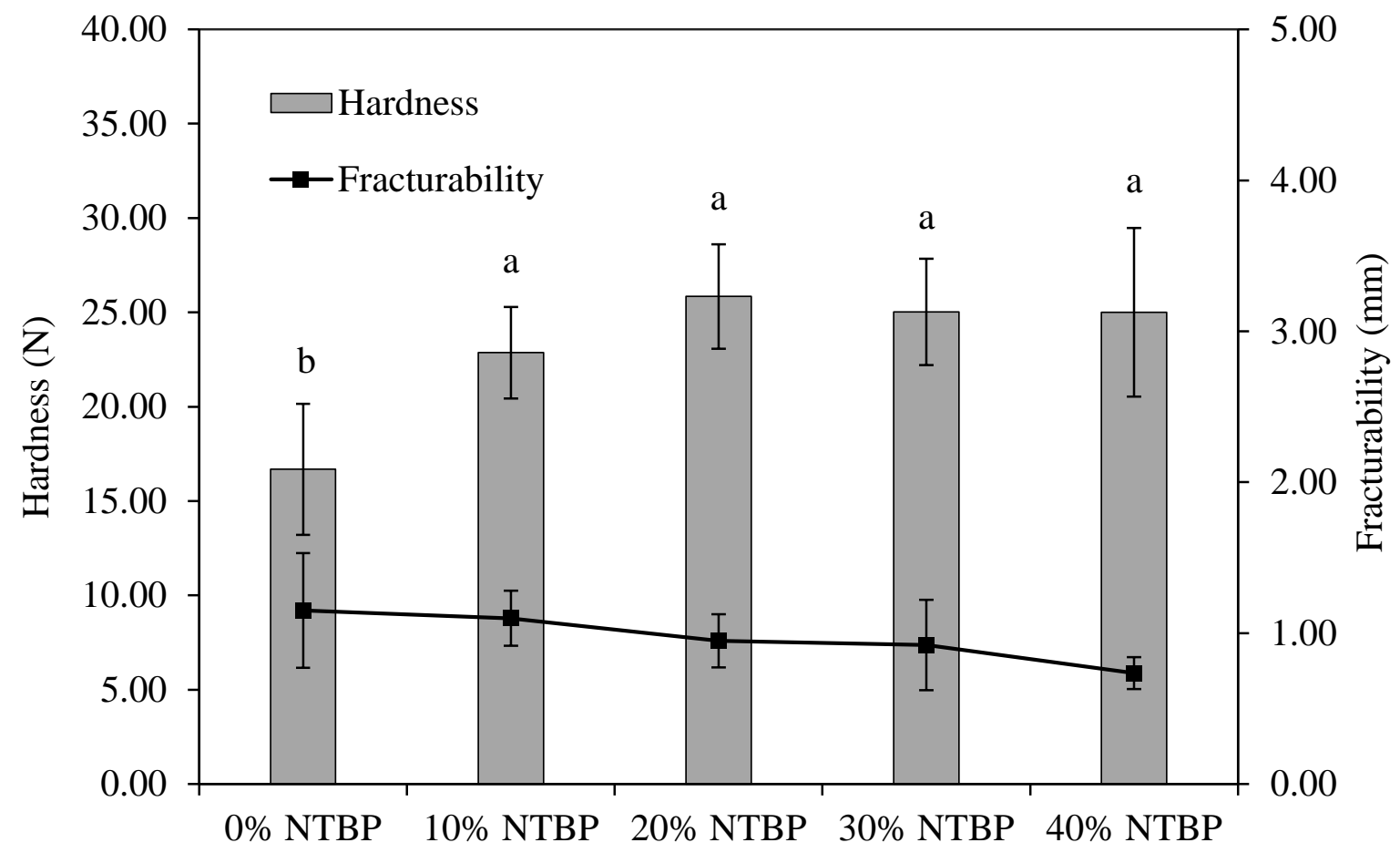

Figure 2. Hardness and fracturability of cashew nut cookies substituted with different NTBP levels.

\section{Chemical properties of cashew nut cookies substituted with Nile tilapia bone powder}

The composition of cashew nut cookies containing with NTBP at different ratios is shown in Table 2 . The major components of the NTBP was: carbohydrate $(86.37 \%)$ and protein $(10.55 \%)$, while moisture $(0.83 \%)$, fat $(1.87 \%)$, crude fiber $(0.009 \%)$ and ash $(0.39 \%)$ were the common minor components (Table 2$)$. Moisture content, protein, fat, fiber and ash displayed an increasing trend, along with the increasing levels of TPBP. All results showed that there was a significant difference $(P \leq 0.05)$ between substituted cookies and unsubstituted cookies. Except with regards to fat content, which was not significantly changed. On the other hand, a reverse trend was found for carbohydrate nutrients. A decrease in carbohydrate values was noticed as NTBP levels increased in the cookies $(P \leq 0.05)$. Moreover, the moisture content of the cashew nut cookies substituted with NTBP ranged from $1.40 \%$ to $2.90 \%$. The highest moisture content level was found in the cookies made of $40 \%$ TFPB $(P \leq 0.05)$. 
Table 2. Proximate composition of cashew nut cookies substituted with different NTBP levels.

\begin{tabular}{lcccccc}
\hline \multirow{2}{*}{ Samples } & \multicolumn{5}{c}{ Compositions (g/100) } \\
\cline { 2 - 7 } & Moisture & Protein & Fat & Fiber & Ash & Carbohydrate \\
\hline NTBP & $0.83 \pm 0.01$ & $10.55 \pm 0.47$ & $1.87 \pm 0.11$ & $0.009 \pm 0.00$ & $0.39 \pm 0.14$ & $86.37 \pm 0.53$ \\
$0 \%$ NTBP & $1.40 \pm 0.15^{\mathrm{d}}$ & $8.22 \pm 0.12^{\mathrm{c}}$ & $26.79 \pm 0.06^{\mathrm{a}}$ & $0.13 \pm 0.02^{\mathrm{c}}$ & $2.49 \pm 0.09^{\mathrm{c}}$ & $60.35 \pm 0.20^{\mathrm{a}}$ \\
$10 \%$ NTBP & $1.60 \pm 0.05^{\mathrm{c}}$ & $9.08 \pm 0.05^{\mathrm{b}}$ & $26.81 \pm 0.72^{\mathrm{a}}$ & $0.13 \pm 0.01^{\mathrm{c}}$ & $5.63 \pm 2.27^{\mathrm{b}}$ & $56.77 \pm 1.78^{\mathrm{b}}$ \\
$20 \%$ NTBP & $2.57 \pm 0.07^{\mathrm{b}}$ & $9.15 \pm 0.03^{\mathrm{ab}}$ & $27.21 \pm 0.33^{\mathrm{a}}$ & $0.14 \pm 0.01^{\mathrm{c}}$ & $6.76 \pm 0.16^{\mathrm{b}}$ & $54.57 \pm 0.28^{\mathrm{c}}$ \\
$30 \%$ NTBP & $2.72 \pm 0.05^{\mathrm{b}}$ & $9.20 \pm 0.03^{\mathrm{ab}}$ & $27.40 \pm 0.43^{\mathrm{a}}$ & $0.18 \pm 0.01^{\mathrm{b}}$ & $11.96 \pm 0.05^{\mathrm{a}}$ & $48.73 \pm 0.42^{\mathrm{d}}$ \\
$40 \%$ NTBP & $2.90 \pm 0.04^{\mathrm{a}}$ & $9.24 \pm 0.08^{\mathrm{a}}$ & $27.57 \pm 0.58^{\mathrm{a}}$ & $0.20 \pm 0.01^{\mathrm{a}}$ & $12.91 \pm 0.08^{\mathrm{a}}$ & $47.17 \pm 0.57^{\mathrm{d}}$ \\
\hline
\end{tabular}

Note: In each column, different letters represent significant differences $(P \leq 0.05)$.

From Table 2 it can be seen that the protein content of the cookies ranged from $8.22-9.27 \%$. Fat content ranges from between $26.79-27.57 \%$, but the results are not significantly different $(P>0.05)$. The average amount of crude fiber in the cookies ranged from 0.13 to $0.20 \%$. The ash content of the cashew nut cookies ranged from 2.49 to $12.91 \%$, and it was at its highest level with cookies containing $40 \%$ NTBP. The higher ash content of the substituted cookies indicates that the cashew nut cookies had a higher mineral content than the control wheat cookies and could be used as alternative mineral source in several food products. The carbohydrate content of the samples ranged between 47.17 and $60.35 \%$. Cookie samples with $40 \%$ NTBP had the lowest carbohydrate content (47.17\%), while the samples without NTBP had the highest value $(60.35 \%)$.

The calcium content of tilapia fishbone, from different sources, is shown in Figure 3a. As previously works, the amount of calcium in the Nile tilapia bone powder was within a range of 29-250 mg/g (Abdel-Moemin, 2015, Prapasuwannakul, 2019, Techochatchawal et al., 2009), which is in agreement with the results of present study. The calcium content in Nile tilapia bone powder in this study was found to be at $181.42 \mathrm{mg} / \mathrm{g}$. Additionally, the effect of NTBP on the calcium content of cashew nut cookies is shown in Figure $3 b$. Interestingly, the calcium content of enriched cookies was significantly more than wheat cookies. The lowest calcium content $(0.2 \mathrm{mg} / \mathrm{g})$, was found in the control cookies. Further, the highest calcium content in cashew nut cookies was observed at $20 \%$ NTBP, with a value of $19.02 \mathrm{mg} / \mathrm{g}(P \leq 0.05)$. It was pointed out that cookies subtitled with NTBP at $20 \%$ had the increase in calcium level by $95-$ fold compared to the control ones. 

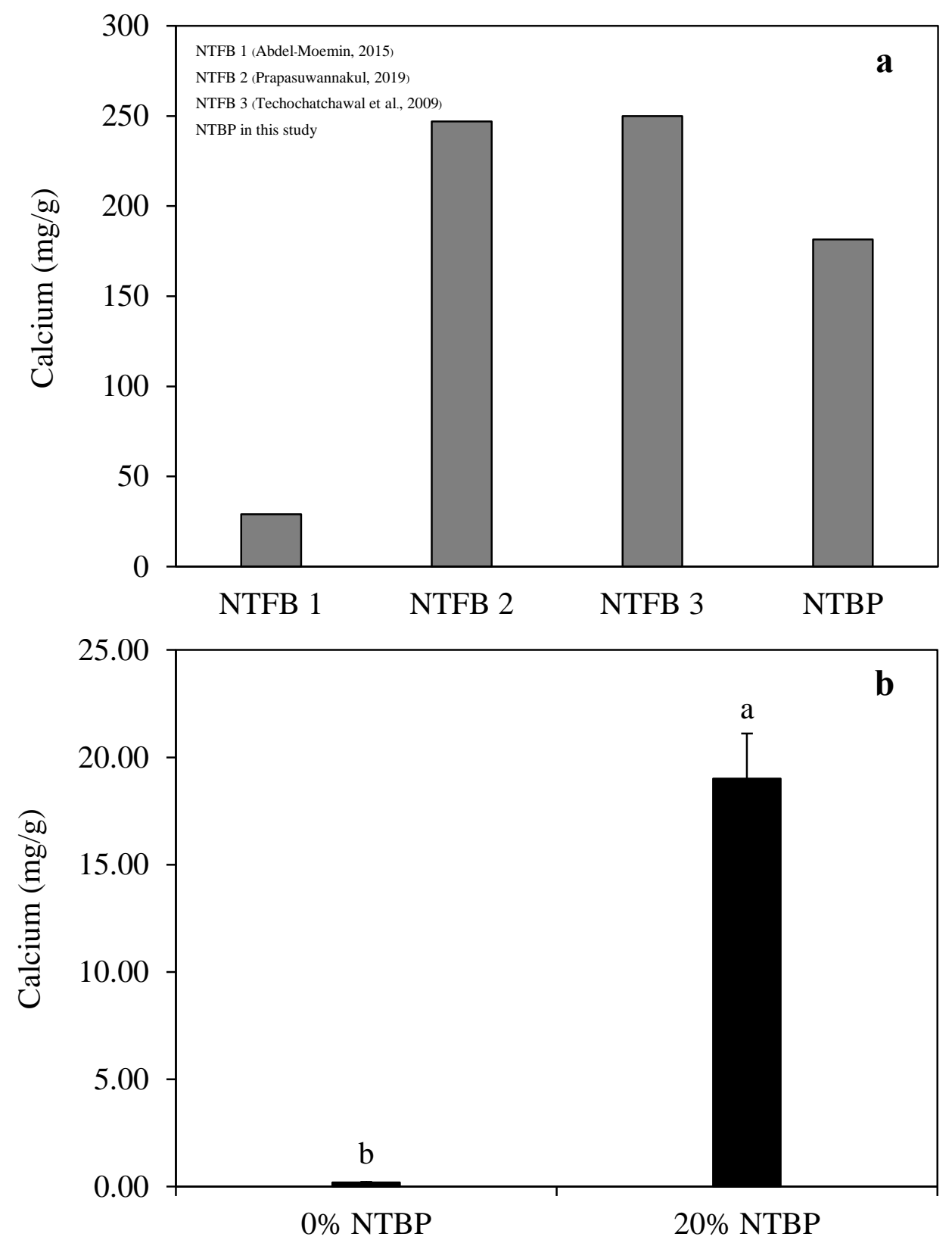

Figure 3. Calcium content of (a) Nile tilapia bone from various sources and (b) the control cashew nut cookie and cookie substituted with $20 \%$ NTBP.

Sensory evaluation of cashew nut cookies substituted with Nile tilapia bone powder

The average scores for sensory attributes, in terms of appearance, color, flavor, taste, texture, and overall liking for cashew nut cookies enriched with NTBP, at different levels, is depicted in Table 3. 
Table 3. Sensory characteristics of cashew nut cookies substituted with different NTBP levels.

\begin{tabular}{llllllc}
\hline \multirow{2}{*}{ Samples } & \multicolumn{5}{c}{ Sensory characteristics } \\
\cline { 2 - 6 } & Appearance & Color & Flavor & Taste & Texture & $\begin{array}{c}\text { Overall } \\
\text { liking }\end{array}$ \\
\hline $0 \%$ NTBP & $7.2 \pm 1.26^{\mathrm{a}}$ & $7.0 \pm 1.22^{\mathrm{a}}$ & $7.0 \pm 1.02^{\mathrm{a}}$ & $7.1 \pm 1.31^{\mathrm{a}}$ & $7.1 \pm 1.10^{\mathrm{a}}$ & $7.4 \pm 0.99^{\mathrm{a}}$ \\
$10 \%$ NTBP & $7.4 \pm 1.30^{\mathrm{a}}$ & $7.0 \pm 1.16^{\mathrm{a}}$ & $6.9 \pm 1.17^{\mathrm{a}}$ & $7.3 \pm 1.11^{\mathrm{a}}$ & $7.0 \pm 1.03^{\mathrm{a}}$ & $7.4 \pm 0.82^{\mathrm{a}}$ \\
$20 \%$ NTBP & $7.3 \pm 1.26^{\mathrm{a}}$ & $7.1 \pm 1.08^{\mathrm{a}}$ & $6.7 \pm 1.21^{\mathrm{a}}$ & $6.7 \pm 1.29^{\mathrm{ab}}$ & $6.7 \pm 1.44^{\mathrm{ab}}$ & $7.0 \pm 1.22^{\mathrm{ab}}$ \\
$30 \%$ NTBP & $7.4 \pm 1.16^{\mathrm{a}}$ & $7.3 \pm 1.21^{\mathrm{a}}$ & $6.7 \pm 1.23^{\mathrm{a}}$ & $6.3 \pm 1.37^{\mathrm{b}}$ & $6.0 \pm 1.59^{\mathrm{b}}$ & $6.7 \pm 1.39^{\mathrm{b}}$ \\
$40 \%$ NTBP & $7.3 \pm 1.12^{\mathrm{a}}$ & $7.1 \pm 1.06^{\mathrm{a}}$ & $6.5 \pm 1.01^{\mathrm{a}}$ & $6.3 \pm 1.32^{\mathrm{b}}$ & $6.2 \pm 1.38^{\mathrm{b}}$ & $6.5 \pm 1.11^{\mathrm{b}}$ \\
\hline
\end{tabular}

Note: In each column, different letters represent significant differences $(P \leq 0.05)$.

The sensory evaluation revealed no significant change $(P>0.05)$ in the following attributes: appearance, color, and flavor in the cookies. Whereas, there were significantly different results with regards to the sensory scores of taste, texture, and overall liking between the control and substituted samples $(P \leq 0.05)$. This relates to the hard and brittle texture of cookies made using NTBP at the higher levels (Figure 2). Moreover, the lower score in taste, texture and overall liking was found with cookies enriched with NTBP at levels of 30-40\%. When compared with the cookies without NTBP, a substitution level of NTBP at $20 \%$ produced no significantly different reaction from participants with regards to all favorable attributes. Based on the above results, the panelists indicated that cashew nut cookies substituting 20\% NTBP were the most acceptable.

\section{DISCUSSION}

The NTBP used in this study was creamy-colored, while the wheat flour was white in color; as a result the lightness of cookies decreased when NTBP powder was added. In addition, the NTBP powder was rich in carbohydrate $(86.37 \%)$ and protein $(10.55 \%)$ content; these are the components that can be generated as a non-enzymatic browning reaction, such as with the Maillard reaction and caramelization of cookies during the baking process. Consequently, the lightness of the cookies was adversely affected by the protein content, and they developed a darker color as a result of the Maillard reaction (Chevallier et al., 2000). Therefore, a reduction in the brightness, yellowness, and whiteness as well as an increase in redness of the cookies, with the addition of the highest level of NTBP, was obviously seen. From the results gathered, it has been indicated that the color of the cashew nut cookies was slightly affected by increased levels of NTBP. With regard to the effect of calcium content on color of cookies, as the substitution of NTBP was increased, the $L^{*}$ values and whiteness of samples declined gradually. The changes in the color of the sample are mainly due to the typical NTBP, giving a light yellowish white powder. It was in correspondence 
with the Nile Tilapia bone powder (Hemung, 2013, Prapasuwannakul, 2019) and Silver carp bone (Yin et al., 2015). As mentioned above, fish bone has a high calcium compound, which exhibit difficult to dissolve in water. Thus, the effect of calcium content on color can be attributed to the fact that the NTBP particles do not allow light to pass through sample (Yin et al., 2014). Subsequently, the obtained cookies with higher NTBP level showed more darker color. Similar finding has been reported by Yin et al. (2014) demonstrated that the addition of micro- and nano-scale fish bone resulted in a decreasing in the $L^{*}$ value and whiteness of surimi gel. Li et al. (2018) also reported that both lightness and whiteness values of rabbit meat batter gels were decreased as the amount of rabbit bone increased.

The spread ratio of cashew nut cookie was found to be the highest value when addition NTBP at 40\%. The viscosity of the dough effected the obtained spread ratio result from the cookies (Miller et al., 1997). Aziah et al. (2012) indicated that a better spread ratio for cookies during baking can be achieved if the dough has a minor initial viscosity. Thus, when more NTBP was added to the cookie dough the mixture produced lower hydration levels, which having a slightly viscosity of the dough and consequently a higher spread rate. Similar results have been reported for the production of flaxseed and cinnamon cookies (Abdel-Moemin, 2015), amaranth cookies (Chauhan et al., 2016) and legume cookies (Aziah et al., 2012). Higher NTBP content increased the hardness of the substituted cashew nut cookies. This might have been the effect of adding NTBP, which requires greater amounts of water to obtain a better cookie dough, and the prepared NTBP typically had a harsh consistency. Therefore, this resulted in the hardness of cookies increasing, when compared to the control group. On the other hand, the substitution of cookies with NTBP caused a decrease in the fracturability of cookies. In addition, the lowest level of fracturability was noticed in cookies at $40 \%$ NTBP. The results indicated that cashew nut cookies substituted with NTBP stay characteristically rigid and brittle. Similar findings were reported by Benjakul and Karnjanapratum (2018), who showed that the addition of tuna bone bio-calcium powder caused whole wheat crackers to develop a harder texture.

As increasing the NTBP level, the moisture content of cashew nut cookies increased, this was probably due to the addition of fish bone powder, which has the quality of hygroscopicity, and so absorbs water from the environment. Difference in chemical composition, with respect to the replacement of fish bone powder, has also been reported for fish crackers (Prapasuwannakul, 2019), whole wheat crackers (Benjakul and Karnjanapratum, 2018) and sausage (Hemung and Sriuttha, 2014). The cashew nut cookies with $20 \%$ NTBP showed drastically increased levels of calcium content, because of the higher calcium content of NTBP. Similar trends were observed in the tuna bio-calcium fortified crackers (Benjakul and Karnjanapratum, 2018) and the fish bone enriched flaxseed and 
cinnamon cookies (Abdel-Moemin, 2015). Additionally, the cashew nut cookies contained NTBP at levels of $30-40 \%$ that gave the lowest score of sensorial attributes, this result indicated that a negative effect of some desirable characteristics, including flavor, taste, and texture of cashew nut cookies was obviously noticed with an increase in the NTBP content. Since the characteristic of NTBP in the present study is quite a gritty powder $(250 \mu \mathrm{m})$, which is classified as coarse particles (>100 $\mu \mathrm{m}$ ) (Yin et al., 2016). Consequently, the panelists could be detected a sandiness $\square$ like mouthfeel in the sample. Thus, this is the reason that the cookies at 30-40\% NTBP gained a lower organoleptic score. It should be noted that decreasing particle size of fish bone resulted in a better the sensory qualities of food products (Yin et al., 2014, 2016). A similar observation has been documented by Prapasuwannakul (2019), found that the addition of fish bone (at level of $0 \%, 15 \%, 20 \%$, and $25 \%$ ) in fish snacks decreased the sensorial acceptance of them when compared to the control crackers.

\section{CONCLUSION}

The replacement of NTBP in cashew nut cookies has improved their nutritional properties. All of the enriched cookies showed higher levels of hardness and spread ratio than the control cookies. The color parameters $\left(L^{*}, a^{*}\right.$, $b^{*}$, and whiteness) of the cookies were influenced by the NTBP level. In addition, the cookies enriched with NTBP generally had a higher moisture, protein, fat, crude fiber, and ash composition, when compared to the control wheat cookies. In addition, the NTBP substituted cookies were rich in calcium content and also received acceptable sensory attribute scores at a $20 \%$ substitution level. This indicates that it is possible to produce calcium rich cookies by enriching them with Nile tilapia bone powder.

\section{ACKNOWLEDGEMENTS}

This research was supported by a grant from the Office of the Permanent Secretary, Ministry of Higher Education Science Research and Innovation, Thailand. The authors would like to acknowledge the School of Agriculture and Natural Resources, University of Phayao for providing the facilities.

\section{REFERENCES}

Abdel-Moemin, A.R. 2015. Healthy cookies from cooked fish bones. Food Bioscience. 12: 114-121. https://doi.org/10.1016/j.fbio.2015.09.003

AOAC. 2012. Official method of analysis. $19^{\text {th }} \mathrm{ed}$. Washington, DC: Association of Official Analytical Chemists. 
Asikin, A.N., Kusumaningrum, I., and Hidayat, T. 2019. Effect of knife-fish bone powder addition on characteristics of starch and seaweed kerupuk as calcium and crude fiber sources. Current Research in Nutrition and Food Science Journal. 7(2): 584-599. https://doi.org/10.12944/CRNFSJ.7.2.27

Aziah, N., Noor, M., and Ho, L.H. 2012. Physicochemical and organoleptic properties of cookies incorporated with legume flour. International Food Research Journal. 19(4) : 1539-1543.https://doi.org/10.1080/23311932. 2016.1172389

Benjakul, S., and Karnjanapratum, S. 2018. Characteristics and nutritional value of whole wheat cracker fortified with tuna bone bio-calcium powder. Food Chemistry. 259: 181-187. https://doi.org/10.1016/j.foodchem.2018.03.124

Chauhan, A., Saxena, D.C., Singh, S., and Yildiz, F. 2016. Physical, textural, and sensory characteristics of wheat and amaranth flour blend cookies. Cogent Food \& Agriculture. 2(1): 1-8. https://doi.org/10.1080/23311932.2015. 1125773

Cheng, Y.F., and Bhat, R. 2016. Functional, physicochemical and sensory properties of novel cookies produced by utilizing underutilized jering (Pithecellobium jiringa Jack.) legume flour. Food Bioscience. 14: 54-61. https://doi.org/10.1016/j.fbio.2016.03.002

Chevallier, S., Colonna, P., Della Valle, G. and Lourdin, D. 2000. Contribution of major ingredients during baking of biscuit dough systems. Journal of Cereal Science. 31(3): 241-252. https://doi.org/10.1006/jcrs.2000.0308

Gooch, J. W. 2011. Whiteness Index. In: Gooch J.W., editor. Encyclopedic Dictionary of Polymers. New York (NY): Springer.p. 811. https://doi.org/ 10.1007/978-1-4419-6247-8_12823

Gupta, M., Bawa, A.S., and Abu-Ghannam, N. 2011. Effect of barley flour and freeze-thaw cycles on textural nutritional and functional properties of cookies. Food and Bioproducts Processing. 89( 4: 520-527. https:// doi.org/ 10.1016/j.fbp.2010.07.005

Hemung, B.-O., Yongsawatdigul, J., Chin, K.B., Limphirat, W., and Siritapetawee, J. 2018. Silver carp bone powder as natural calcium for fish sausage. Journal of Aquatic Food Product Technology. 27(3): 305-315. https://doi.org/10.1080/10498850.2018.1432733

Hemung, B., 2013. Properties of tilapia bone powder and its calcium bioavailability based on transglutaminase assay. International Journal of Bioscience, Biochemistry and Bioinformatics. 3: 306-309. https://doi.org/ 10.7763/IJBBB.2013.V3.219

Hemung, B. and Sriuttha, M. 2014. Effects of tilapia bone calcium on qualities of tilapia sausage. Kasetsart Journal - Natural Science. 48: 790-798.

Li, S., He, Z., and Li, H. 2018. Effect of nano-scaled rabbit bone powder on physicochemical properties of rabbit meat batter. Journal of the Science of Food and Agriculture. 98(12): 4533-4541. 
Miller, R.A., Hoseney, R.C., and Morris, C.F. 1997. Effect of formula water content on the spread of sugar-snap cookies. Cereal Chemistry. 74(5): 669671.

Mounjouenpou, P., Ngono Eyenga, S.N.N., Kamsu, E.J., Bongseh Kari, P., Ehabe, E.E., and Ndjouenkeu, R. 2018. Effect of fortification with baobab (Adansonia digitata L.) pulp flour on sensorial acceptability and nutrient composition of rice cookies. Scientific African. 1: 1-9.

Nawaz, A., Xiong, Z., Xiong, H., Chen, L., Wang, P. - k., Ahmad, I., Hu, C., Irshad, S. and Ali, S.W. 2019. The effects of fish meat and fish bone addition on nutritional value, texture and microstructure of optimised fried snacks. International Journal of Food Science \& Technology. 54(4): 10451053.

Nemati, M., Huda, N., and Ariffin, F. 2017. Development of calcium supplement from fish bone wastes of yellowfin tuna (Thunnus albacares) and characterization of nutritional quality. International Food Research Journal. 24(6): 2419-2426.

Prapasuwannakul, N. 2019. Consumer acceptance of nutritional enrichment of fish crackers used for snacks with fish bones. In: Goonetilleke, R.S., and Karwowski, W., editors. Advances in Physical Ergonomics \& Human Factors. AHFE 2018. Advances in Intelligent Sytem and Computing. Cham: Springer. p.242-250. https://doi.org/10.1007/978-3-319-944845_26

Sharma, P., Velu, V., Indrani, D., and Singh, R.P. 2013. Effect of dried guduchi (Tinospora cordifolia) leaf powder on rheological, organoleptic and nutritional characteristics of cookies. Food Research International. 50(2): 704-709.

Techochatchawal, K., Therdthai, N., and Khotavivattana, S. 2009. Development of calcium supplement from the bone of Nile Tilapia (Tilapia nilotica). Asian Journal of Food and Agro-Industry. 2(4): 539-546.

Yin, T., Du, H., Zhang, J., and Xiong, S. 2016. Preparation and characterization of ultrafine fish bone powder. Journal of Aquatic Food Product Technology. 25(7): 1045-1055.

Yin, T., Park, J.W., and Xiong, S. 2015. Physicochemical properties of nano fish bone prepared by wet media milling. LWT - Food Science and Technology. 64 (1): 367-373.

Yin, T., Reed, Z. H., and Park, J.W. 2014. Gelling properties of surimi as affected by the particle size of fish bone. LWT - Food Science and Technology. 58(2): 412-416. 